\title{
Article \\ pH-Sensitive Silver-Containing Carbon Dots Based on Folic Acid
}

\author{
Qinhai Xu, Kang Li and Peng Wang *
}

check for

updates

Citation: Xu, Q.; Li, K.; Wang, P. $\mathrm{pH}$-Sensitive Silver-Containing Carbon Dots Based on Folic Acid Materials 2022, 15, 1880. https:/ / doi.org/10.3390/ma15051880

Academic Editor: Jinheung Kim

Received: 18 January 2022

Accepted: 25 February 2022

Published: 3 March 2022

Publisher's Note: MDPI stays neutral with regard to jurisdictional claims in published maps and institutional affiliations.

Copyright: (C) 2022 by the authors. Licensee MDPI, Basel, Switzerland. This article is an open access article distributed under the terms and conditions of the Creative Commons Attribution (CC BY) license (https:// creativecommons.org/licenses/by/ $4.0 /)$.
Department of Chemistry, Renmin University of China, Beijing 100872, China; 2017000460@ruc.edu.cn (Q.X.); 2020102318@ruc.edu.cn (K.L.)

* Correspondence: wpeng_chem@ruc.edu.cn; Tel.: +86-10-6251-6604

\begin{abstract}
Herein, Ag-containing carbon dots (Ag-CDs) was synthesized based on folic acid. In a neutral solution, its fluorescence emission owns a structure fixing fluorescent species with the emission maximum at $400 \mathrm{~nm}$ and an excitation-wavelength dependent fluorescent species, respectively. By comparing fluorescent emission and excitation spectra, the electronic absorption origins of these fluorescent species were assigned. With the assistance of UV-Vis absorption and XPS, the $\mathrm{pH}$-regulating fluorescence mechanism of Ag-CDs was studied and proposed. A particularly strong fluorescence emitter was observed at $\mathrm{pH} \sim 12$ with a mixing coordination structure as $\mathrm{Ag}\left(\mathrm{CDs}-\mathrm{NH}_{2}\right) \mathrm{OH}$. The as-prepared Ag-CDs might be developed into a fluorescent sensor, especially at extremely basic conditions.
\end{abstract}

Keywords: Ag-containing carbon dots; $\mathrm{pH}$ sensor; fluorescence emission; structural mechanism; spectroscopy

\section{Introduction}

Carbon dots (CDs), a kind of fluorescent carbon-based materials, have attracted great attention recently for a wide variety of chemical and biological applications, such as biosensing, bioimaging, drug delivery, photodynamic therapy, photocatalysis and electrocatalysis, due to their good fluorescence quantum yield, excellent solubility, high biocompatibility, nontoxicity, and good photochemical stability [1-4]. Generally, almost all CDs show excitation-dependent fluorescence [5]. Among many proposed origins of the excitation-dependent fluorescence, the surface functional group of CDs draws the most attention. Nie et al. suggested that the surface functional groups of $C D$ s, such as $C=O$ and $\mathrm{C}=\mathrm{N}$, can efficiently introduce new energy levels for electron transitions and contribute to the main origin of excitation-dependent fluorescence [6]. Wen et al. proposed that the excitation-wavelength-dependent fluorescence arises from the abundant carboxyl functional groups on the surface [7]. Wang et al. found that no matter what kind of method is used to fabricate CDs, all their fluorescence originates from special edge states consisting of several carbon atoms on the edge of the carbon backbone and surface carbonyl or carboxyl groups as well [8]. Lei et al. demonstrated that the functional groups with different degrees of oxidation on the surface of CDs lead to the variation in emission wavelength by changing the energy band gap of CDs [9]. Sharma et al. proposed that surface functional groups determining aggregation are the origin of discrete multiple electronic states for the excitation-dependent emission in carbon nanodots [10]. In addition to the excitation-dependent fluorescence, CDs sometimes have another shorter wavelength emissive component without excitation-dependent behavior. This excitation-independent shorter wavelength emission is found to depend on the states of surface amino-groups, while the excitation-dependent longer wavelength emission is due to the presence of carboxyl or hydroxyl groups $[5,11]$. The roles of N-doping in forming the emission states of CDs were reviewed by Wang et al. [2]. In this review, either N-doping directly into the carbon skeleton, or $\mathrm{Mg} / \mathrm{N}, \mathrm{P} / \mathrm{N}$, and $\mathrm{S} / \mathrm{N}$ co-doping were demonstrated to be good strategies 
to bring more excellent properties to the resulting CDs. Some other researches showed that N-doping CDs could be developed into a potential fluorescent probe for detecting environmental $\mathrm{Hg}^{2+}$ ions [12] or pathogenic bacteria at an acidic $\mathrm{pH}$ [13]. Recently, Khan et al. reported $\mathrm{N}$-doping green-emissive CDs synthesized via a solid-state reaction method with good thermal stability and much better quantum yield in ethanol than in water [14].

The fluorescence of CDs is usually found to be $\mathrm{pH}$-dependent, which is attributed to the reversible protonation and deprotonation of functional groups on the surface of CDs [15-19] and the aggregation of CDs [17,20,21]. Among these, N-doping also plays a very important role. For example, CDs prepared by Maillard reaction with L-tryptophan as $\mathrm{N}$ resources own excellent photoluminescence stability and stable $\mathrm{pH}$-dependence and could be used to selectively detect $\mathrm{Cr}$ (VI) in tap water [22]. Jute-derived fluorescent surface-quaternized CDs were developed as fluorescent nanobuttons to detect aqueous chromium (VI) and a pH-responsive drug release carrier [23]. CDs with polyethyleneimine (PEI) as a surface passivation agent exhibits $\mathrm{pH}$-responsive optical properties [24].

In addition, the environmental metal ions affect the fluorescence of CDs too, and this has been used to develop a CDs-based metal ion sensor. Among the metal elements studied, $\mathrm{Ag}^{+}$was found to significantly enhance the fluorescence of CDs by chelating $\mathrm{Ag}^{+}$ with surface functional groups [25-27]. Therefore, directly doping $\mathrm{Ag}^{+}$into CDs during preparation is a promising way to develop Ag-containing CDs (Ag-CDs) [28-30].

The doped $\mathrm{Ag}^{+}$may occupy part of the surface functional groups of CDs, which generally are also sensitive to the environmental $\mathrm{pH}$ values. However, the $\mathrm{pH}$ effect on the fluorescence behavior of Ag-CDs has not been studied yet. In this study, a hydrothermal method was applied to synthetize Ag-containing carbon dots (Ag-CDs) by using folic acid (FA) as a carbon source and sliver nitrate as a silver source. The compositional and structural characterizations by Fourier transform infrared absorption spectroscopy (FT-IR) and X-ray photoelectron spectroscopy (XPS) confirmed the primary amine and carboxyl groups co-existing on the surface of prepared Ag-CDs. By comparing their UVVis absorption, fluorescence emission and excitation spectra, the electronic absorption origins of the two fluorescent species observed in neutral solution were assigned. With the assistance of UV-Vis absorption and XPS, the $\mathrm{pH}$ effect on the fluorescence of Ag-CDs was studied. A very strong fluorescence species observed at $\mathrm{pH} \sim 12$ was deduced to be with mixing coordination structure as $\mathrm{Ag}\left(\mathrm{CDs}-\mathrm{NH}_{2}\right) \mathrm{OH}$. Finally, the $\mathrm{pH}$-regulating fluorescence mechanism of Ag-CDs was proposed. It is worth noting that two of the three fluorescent species are Ag-containing.

In this research, Ag-containing CDs based on folic acid were prepared, and a more detailed mechanism of its $\mathrm{pH}$-regulating fluorescence was studied and proposed. This contribution might be developed into a fluorescent sensor, especially in extremely basic conditions.

\section{Experimental Section}

\subsection{Reagents and Apparatus}

All the needed reagents and apparatus in the studies were shown in Supplementary Materials.

\subsection{Preparation of Ag-Containing Carbon Dots (Ag-CDs)}

Ag-doped carbon dots (Ag-CDs) were prepared by the one-step hydrothermal method. Firstly, $0.1 \mathrm{~g}$ of folic acid (FA) and $0.2 \mathrm{~g}$ of $\mathrm{AgNO}_{3}$ were dissolved in $30 \mathrm{~mL}$ of ultra-pure water. Then, the solutions were transferred into an autoclave $(50 \mathrm{~mL})$ and heated at $200{ }^{\circ} \mathrm{C}$ for $12 \mathrm{~h}$. The resulting suspensions were centrifuged at $15000 \mathrm{rpm}$ for 10 minutes, filtered by micro-filtration membranes $(\phi=0.22 \mu \mathrm{m})$ three times, and then dialyzed (MWCO $1000 \mathrm{Da})$ for one day. The purified Ag-CDs were obtained and stored.

\subsection{Effect of $p H$ on the Fluorescence of $A g-C D s$}

To investigate the effect of $\mathrm{pH}$ on the fluorescence properties of Ag-CDs, concentrated $\mathrm{NaOH}$ and $\mathrm{H}_{2} \mathrm{SO}_{4}$ aqueous solutions were used to adjust the $\mathrm{pH}$ values of $\mathrm{Ag}-\mathrm{CD}$ solution 
as $0.74,1.32,2.25,3.09,4.06,5.06,5.89,6.37,7.00,8.19,9.04,9.99,11.10,12.15,12.97$, and 13.50 , respectively. The $\mathrm{pH}$ value was measured with a digital $\mathrm{pH}$ meter (PHS-3C, YOKE INSTRUMENT, Shanghai, China). The reversibility of the effect of $\mathrm{pH}$ on the fluorescence of Ag-CDs was investigated by changing the $\mathrm{pH}$ values between $\mathrm{pH}=12.15$ and $\mathrm{pH}=2.25$ by repeatedly adding concentrated $\mathrm{NaOH}$ or $\mathrm{H}_{2} \mathrm{SO}_{4}$. The fluorescence emission spectra were recorded by the fluorescence spectrophotometer (HITACHI F-4600, HITACHI, Tokyo, Japan).

\section{4. pH Fluorescent Test Paper}

In order to evaluate the practical application ability of Ag-CDs as a $\mathrm{pH}$ fluorescent probe, the filter paper was soaked in Ag-CDs solutions for 1 minute and then dried at $90{ }^{\circ} \mathrm{C}$ for $2 \mathrm{~h}$ to obtain the $\mathrm{pH}$ fluorescent test paper. To determine the feasibility of the test paper in various water samples, tap water and ultrapure water were chosen for comparison. Three $\mathrm{pH}$ values were selected for the tests, i.e., 11.15, 12.20 and 13.02. The prepared test papers were soaked in various water samples for $2 \mathrm{~s}$ and were taken out immediately. After staying in the air for $10 \mathrm{~min}$, the fluorescent photographs were taken under UV light.

\section{Results and discussion}

\subsection{Morphology and Composition of Ag-CDs}

To study the morphology of Ag-CDs prepared in this research, a TEM image was measured, as shown in Figure 1a. The TEM image (Figure 1a) of Ag-CDs shows that the prepared Ag-CDs own good dispersity and the particle size had an average diameter of $3.23 \pm 1 \mathrm{~nm}$ (insert (I) in Figure 1a). In addition, the lattice spacing of crystallized Ag-CDs was determined as $0.21 \mathrm{~nm}$ corresponding to the (110) diffraction plane of graphitic carbon (JCPDS cards 26-1076), as shown as insert (II-1) in Figure 1a [31].
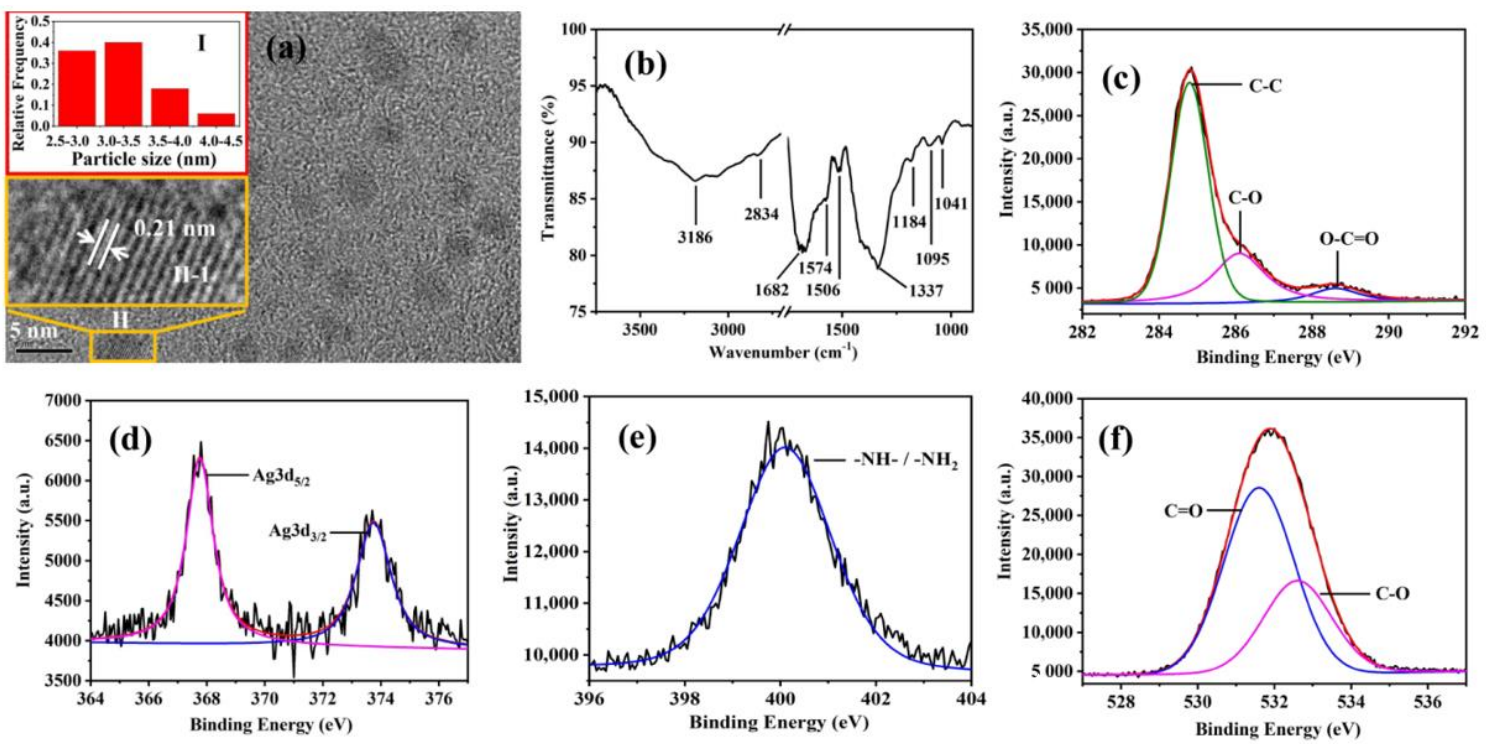

Figure 1. (a) TEM image of Ag-CDs. (Inserts: (I) Particle size distribution histogram of Ag-CDs. (II-1) Magnified image of "II" Ag-CD.) FT-IR spectrum (b), high-resolution XPS spectra of C1s (c), Ag3d (d), N1s (e), and O1s (f), respectively, of Ag-CDs.

To obtain the functional group information, the FT-IR spectrum of Ag-CDs was measured and is presented in Figure $1 \mathrm{~b}$. The moderate and broad bands peaked at 3186 and $2834 \mathrm{~cm}^{-1}$ were assigned as the stretching modes of $\mathrm{O}-\mathrm{H}$ in the carboxyl group and $\mathrm{C}-\mathrm{H}$ on $\mathrm{sp}^{3}$ carbons, respectively, and the broadening and down-shifting of the former peak were due to the hydrogen bonds in existing intra- or inter-particles [32,33]. The strong band peak at $1682 \mathrm{~cm}^{-1}$ was attributed to the stretching mode of the $\mathrm{C}=\mathrm{O}$ group in the carboxyl group [34]. The peaks at 1574 and $1516 \mathrm{~cm}^{-1}$ were assigned as the $C=C$ stretching modes 
of the graphitic backbone of Ag-CDs [35]. The peaks at $1337 \mathrm{~cm}^{-1}$ could be ascribed to the stretching modes of $\mathrm{C}-\mathrm{N}$, which originated from the primary and secondary amine groups attached to the graphitic backbone [36]. The peaks at 1184, 1095, and $1041 \mathrm{~cm}^{-1}$ are assigned as the stretching modes of $\mathrm{C}-\mathrm{O}[6,17,35]$.

The elemental composition of Ag-CDs was determined by XPS (the full XPS spectrum of Ag-CDs is shown in Figure S1 in the Supplementary Materials), and the results for C1s, Ag3d, N1s, and O1s are shown in Figure 1c-f, respectively. In C1s' XPS spectrum (Figure 1c), three peaks at 284.8, 286.2, and $288.4 \mathrm{eV}$ were assigned as the carbon atoms in C-C, C-O, and $\mathrm{O}-\mathrm{C}=\mathrm{O}$ groups, respectively [12,33,37-39]. In the Ag3d spectrum (Figure 1d), the peaks at 367.7 and $373.78 \mathrm{eV}$ were attributed to $\mathrm{Ag} 3 \mathrm{~d}_{5 / 2}$ and $\mathrm{Ag} 3 \mathrm{~d}_{3 / 2}$, respectively, which indicated the presence of $\mathrm{Ag}^{+}[26,40]$. In N1s' spectrum (Figure 1e), the peak at 400.0 was assigned as the $\mathrm{N}$ atoms in $-\mathrm{NH}-/-\mathrm{NH}_{2}$ groups [32,38]. In O1s' spectrum (Figure 1f), the peaks at 531.7 and $532.6 \mathrm{eV}$ were attributed to the carbon atoms in $\mathrm{C}=\mathrm{O}$ and $\mathrm{C}-\mathrm{O}$ groups, respectively [33]. In combination with all the results of FT-IR and XPS, primary and secondary amino ($\left.\mathrm{NH}_{2} /-\mathrm{NH}-\right)$, carboxylic $(-\mathrm{COOH})$, and hydroxyl $(-\mathrm{OH})$ groups were determined to attach to the graphitic carbon backbone of Ag-CDs prepared in this research.

\subsection{Assignment of the Electronic Absorption Origins of the Fluorescent Species of Ag-CDs in Neutral Solution}

Figure 2a shows the absorption spectrum of Ag-CDs in a neutralized aqueous solution. A moderate absorption band range in wavelengths from 275 to $350 \mathrm{~nm}$ and a weaker shoulder range from 350 to $500 \mathrm{~nm}$ were observed. The normalized fluorescence emission spectra of Ag-CDs under excitation at various wavelengths $\left(\lambda_{\mathrm{EX}}\right)$ are shown in Figure $2 b$. Upon excitation at wavelengths of 270-330 nm (thinner black line in Figure 2b), the spectrum seems almost the same as the single band peaked at $\sim 400 \mathrm{~nm}$, indicating that a structure-fixing luminescent species exists in this spectral region. When $\lambda_{\mathrm{EX}}$ is $\geq 350 \mathrm{~nm}$ and moves toward red, the emission spectra show characteristic excitation-wavelength-dependent spectral behavior, i.e., moving towards red too. This typical fluorescent species observed in many carbon dots was mainly attributed to the excitation-wavelength selecting size dependence of emissive traps on the surface of CDs [41,42]. Notably, upon excitation at $350 \mathrm{~nm}$, the emission spectrum shows dual-emission characteristics. Such spectral pattern was used as a standard region for $\mathrm{pH}$ effect study in the following.
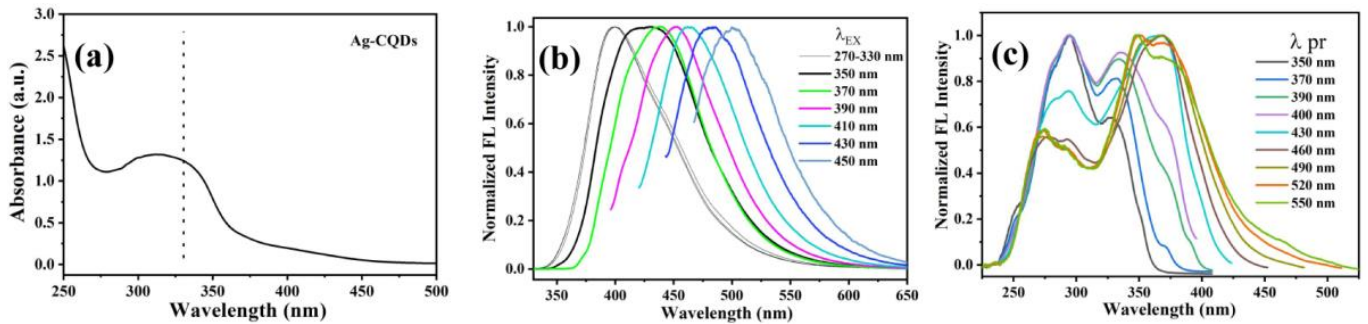

Figure 2. (a) The UV-Vis absorption spectrum, (b) the normalized fluorescent emission spectra under various excitation wavelengths $\left(\lambda_{\mathrm{EX}}\right)$, and (c) the normalized fluorescent excitation spectra under various probed wavelengths $\left(\lambda_{\mathrm{pr}}\right)$ of Ag-CDs in neutralized aqueous solution.

The electronic absorption origins of fluorescent emission of Ag-CDs were studied by fluorescent excitation spectra. The normalized spectra (Figure 2c) were categorized into two groups based on fluorescent probing wavelengths $\left(\lambda_{\text {pr }}\right)$. For the first group, i.e., $\lambda_{\text {pr }}$ in 350-400 $\mathrm{nm}$, the normalized excitation spectra have two bands. The one in the shorter wavelength range $(250-330 \mathrm{~nm})$ that peaked at $294 \mathrm{~nm}$ has almost the same spectral pattern on the blue edges, which mainly corresponds to the structure-fixing fluorescent species and is further ascertained as in 270-330 nm, as shown in Figure 2b. Another one is just constantly red-shifting and intensity-enhancing upon $\lambda_{\text {pr }}$ red-shifting. For the second group, i.e., $\lambda_{\mathrm{pr}}$ in $460-550 \mathrm{~nm}$, the normalized fluorescence excitation spectra have almost the same spectral pattern in the blue region $(250-330 \mathrm{~nm})$ and varied ones in the red region 
(330-500 nm), especially the red-edges, which gradually shift toward longer wavelengths. This fluorescence species and the second one in the first group were assigned together, similar to the typical excitation-wavelength-dependent luminescent species aforementioned.

To summarize, two fluorescent species were determined to exist in Ag-CDs in neutral solution. One has a fixed electronic structure with absorption in 250-330 nm, and the other is an excitation-wavelength-dependent species with absorption in 250-500 nm.

\section{3. $\mathrm{pH}$-Regulating Fluorescent Variation in Ag-CDs}

The $\mathrm{pH}$ effect on fluorescent properties of Ag-CDs was studied by measuring their $\mathrm{UV}-\mathrm{Vis}$ absorption and fluorescence emission spectra at various $\mathrm{pH}$ values in a range of 0.74-13.50. The results are summarized in Figure 3. Under daylight (Figure 3a-I), the aqueous solutions of Ag-CDs are almost colorless at $\mathrm{pH}<12.15$ but gradually become yellowish when $\mathrm{pH} \geq 12.15$. Correspondingly, under UV light $365 \mathrm{~nm}$ (Figure 3a-II), all solutions exhibit blue fluorescence. At extremely acidic and alkaline conditions, i.e., $\mathrm{pH}<2.25$ and $>12.15$, the fluorescent emission becomes obviously weaker, while at $\mathrm{pH} 12.15$, the utmost bright fluorescence is observed, and at all the other $\mathrm{pH}$ values, the fluorescent emission seems the same as each other.
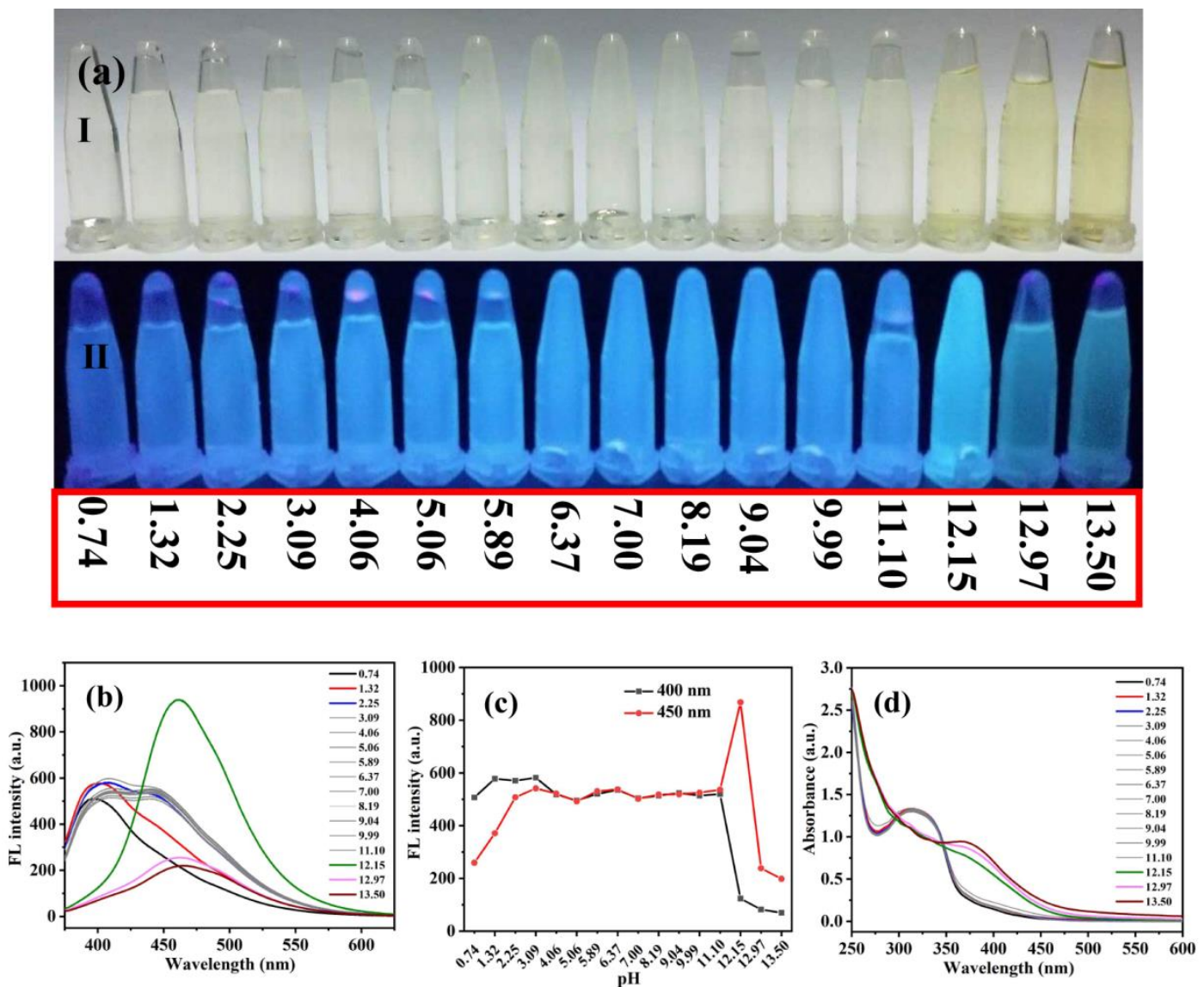

Figure 3. (a) Photographs of Ag-CDs in aqueous solutions at various $\mathrm{pH}$ values under daylight (a-I) and UV light (365 nm, a-II). Fluorescent emission spectra at $\lambda_{\mathrm{EX}} 360 \mathrm{~nm}$ (b), fluorescent intensity probed at 400 and $450 \mathrm{~nm}$ (c), and absorption spectra (d) of Ag-CDs detected at various $\mathrm{pH}$ values.

The fluorescence spectra of Ag-CDs under $\lambda_{\mathrm{EX}} 360 \mathrm{~nm}$ at various $\mathrm{pH}$ values were shown in Figure $3 b$, which were consistent with the luminescent photos in Figure 3a-II. At extremely acidic conditions $(\mathrm{pH}<2.25)$, the spectra show a single-peak band with the emission maximum $\left(\lambda_{\max }\right)$ at $400 \mathrm{~nm}$; at $\mathrm{pH}$ in $2.25-11.10$, the fluorescent spectra show uniform dual-emission characteristics with peaks at 400 and $450 \mathrm{~nm}$, respectively; at $\mathrm{pH} \geq 12.15$, the fluorescent spectra have a single-peak band with $\lambda_{\max }$ at $460 \mathrm{~nm}$, and the 
fluorescent intensity significantly enhances at $\mathrm{pH} 12.15$ and decreases quickly upon the $\mathrm{pH}$ value increasing further. It is worth pointing out that the fluorescent emission at $450 \mathrm{~nm}$ observed in $\mathrm{pH} 2.25-11.10$ has a different origin from the emission at $460 \mathrm{~nm}$ observed in $\mathrm{pH} \geq 12.15$. A more detailed discussion is in Section 3.4.

Fluorescent intensities, probed, respectively, at 400 and $450 \mathrm{~nm}$ were depicted in Figure $3 \mathrm{c}$ versus the variation of $\mathrm{pH}$ values. Apparently, the $450 \mathrm{~nm}$ is a more sensitive probing wavelength for studying $\mathrm{pH}$-effect on fluorescence. Along with the $\mathrm{pH}$ change from 0.74 to 13.50 , three stages were clearly seen, i.e., $\mathrm{pH}$ at $0.74-2.25,2.25-11.10$, and $12.15-13.50$, respectively. The fluorescent intensity correspondingly undergoes the following changes, i.e., gradually increasing, keeping constant, and significantly enhancing and dropping down soon.

The absorption spectra of Ag-CDs at various $\mathrm{pH}$ were shown as in Figure 3d. At a $\mathrm{pH}$ between 0.74 and 11.10 , the spectra seem unchanged. At three extremely alkaline conditions, a different spectral pattern was observed. The obvious collapse of the 300-350 nm peak and the significant increase in the 350-500 nm shoulder (Figure 3d) indicate that a structural change happens particularly upon the $\mathrm{pH}$ changing from 11 to 12 .

\subsection{Structural Mechanism of $p H$-Regulating Fluorescence of Ag-CDs}

The results of FT-IR and XPS (Section 3.1.) indicate that primary amine $\left(-\mathrm{NH}_{2}\right)$, $\mathrm{COOH},-\mathrm{OH}$, and $\mathrm{Ag}^{+}$coexist in the Ag-CDs prepared in this research. By spectral analysis in a neutral solution, as mentioned in Section 3.2., two fluorescent species were deduced to coexist in a neutral solution of Ag-CDs. One has a fixed structure with electronic absorption in the range of 250-330 $\mathrm{nm}$, and the other has wavelength-dependent fluorescent emission properties with absorption in the range of $250-500 \mathrm{~nm}$. The further $\mathrm{pH}$-regulating fluorescence study (Section 3.3.) proves that the extremely acidic and alkaline conditions will cause structural changes, which either quench the fluorescence species of $450 \mathrm{~nm}$ or generate a new fluorescence species emitting at $460 \mathrm{~nm}$. Combining all the aforementioned results, we proposed a $\mathrm{pH}$-regulating and $\mathrm{Ag}^{+}$-containing fluorescent mechanism, as shown in Scheme 1.

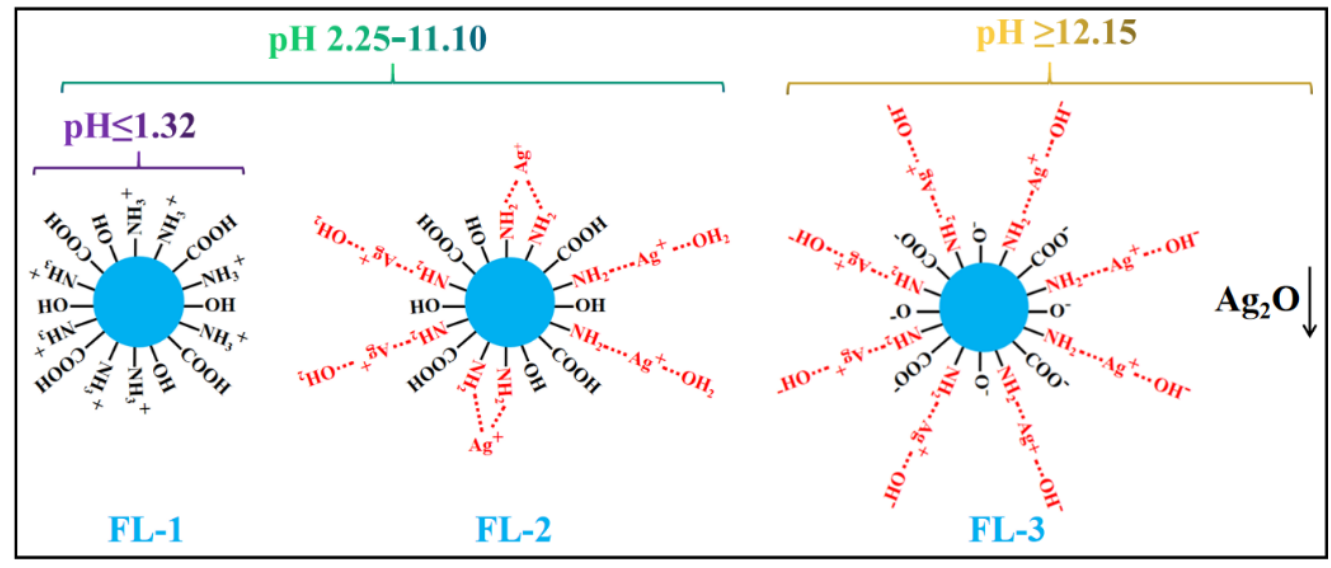

Scheme 1. Proposed structural mechanism of $\mathrm{pH}$-regulated fluorescence of Ag-CDs.

At a $\mathrm{pH}$ in $2.20-11.15$, two fluorescent species coexist in Ag-CDs, i.e., the one free of $\mathrm{Ag}^{+}$with characteristic fluorescence at $400 \mathrm{~nm}$ and the other with the $\mathrm{Ag}^{+}\left(-\mathrm{NH}_{2}\right)_{2}$ group and characteristic fluorescence at $450 \mathrm{~nm}$, which were named FL-1 and FL-2, respectively. These two fluorescent species contribute to the typical dual-emission spectra measured in a neutral solution. When the $\mathrm{pH}$ is at an extremely acidic condition, i.e., $\mathrm{pH} \leq 1.32$, the amino group of FL-2 is thoroughly protonated, and the originally coordinated $\mathrm{Ag}^{+}$might be dissolved in the extremely acidic solution. This causes the fluorescence emission to stop at $450 \mathrm{~nm}$ (seeing Figure $3 \mathrm{~b}, \mathrm{c}$ ). When the $\mathrm{pH}$ is at 12.15 , the concentrated $\mathrm{OH}^{-}$may compete with $-\mathrm{NH}_{2}$ in coordinating with $\mathrm{Ag}^{+}$to form a new intermediate, as proposed in Scheme 1 
as FL-3. The significantly enhancing fluorescence intensity and characteristic emission at $460 \mathrm{~nm}$ differentiate FL-3 from FL-2. Furthermore, at this $\mathrm{pH}$ value, the fluorescence of FL-1 and its corresponding absorption vanish together, indicating that an extremely alkaline condition causes the structural change and the consequential fluorescence quenching of FL-1. When the $\mathrm{pH}$ increases further, the fluorescence intensity of Ag-CDs drops quickly, but the spectral pattern remains unchanged because a more alkaline condition will cause the formed $\mathrm{AgOH}$ to quickly transform into $\mathrm{Ag}_{2} \mathrm{O}$ irreversibly, which is supported by the yellowish color of solutions at extremely alkaline conditions seen under daylight (Figure 3a).

High-resolution X-ray photoelectron spectroscopy (XPS) of Ag3d and N1s at various $\mathrm{pH}$ values (Figure 4) were used to support the proposed mechanisms above.
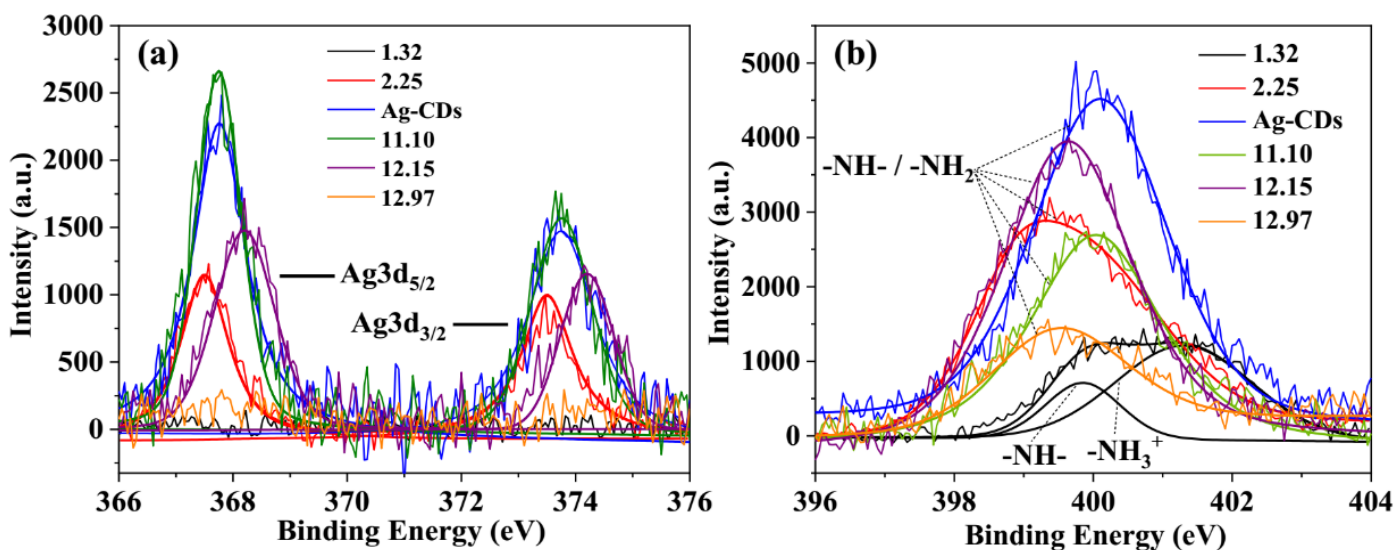

Figure 4. High-resolution XPS spectra of Ag3d (a) and N1s (b) of Ag-CDs at pH 1.32, 2.25, 11.10, 12.15 , and 12.97, respectively.

As shown in Figure $4 \mathrm{a}$, at a $\mathrm{pH}$ of 1.32 , no $\mathrm{Ag}^{+}$signal was observed. This could be explained by the thorough protonation of the amino group by the extremely acidic conditions (as shown as FL-1 in Scheme 1), which causes $\mathrm{Ag}^{+}$to dissolve into the solutions. Upon the $\mathrm{pH}$ increasing, the gradual deprotonation of $-\mathrm{NH}_{3}{ }^{+}$results in the formation of $\mathrm{Ag}\left(-\mathrm{NH}_{2}\right)_{2}{ }^{+}$again, while FL-1 and FL-2 coexist and generate a dual-emission spectral at $\mathrm{pH}$ 2.25-11.10. At a $\mathrm{pH}$ of 2.25, which is the ending point of the transition stage from aqueous $\mathrm{Ag}^{+}$to $\mathrm{Ag}\left(-\mathrm{NH}_{2}\right)_{2}{ }^{+}$, the $\mathrm{Ag}^{+}\left(-\mathrm{NH}_{2}\right)\left(\mathrm{H}_{2} \mathrm{O}\right)$ might exist too. Since the filling capability of a lone pair from an oxygen atom of $\mathrm{H}_{2} \mathrm{O}$ is apparently weaker than that from a nitrogen atom of $-\mathrm{NH}_{2}$ groups, there might be smaller electron binding energy (BE) of Ag3d at pH 2.25 (the red line in Figure 4a) than that at neutral pH (the blue line in Figure 4a). When $\mathrm{pH}$ arrives at 12.15, a new intermediate state forms as proposed as FL-3 in Scheme 1. Higher BE of Ag3d is observed (purple line in Figure 4a). This could be explained by one coordination bond between $\mathrm{Ag}^{+}$and $-\mathrm{NH}_{2}$ being replaced by a covalent bond $\mathrm{Ag}-\mathrm{O}$. When basicity increases further, $\mathrm{AgOH}$ may transform into $\mathrm{Ag}_{2} \mathrm{O}$ irreversibly, which decreases the fluorescence intensity of FL-3 and exhibits a yellowish color correspondingly (seeing the photographs at daylight at $\mathrm{pH} \geq 12.15$ in Figure 3a-I). Reasonably, the XPS signal of Ag3d disappears again at $\mathrm{pH} 12.97$ since most of the coordinated $\mathrm{Ag}^{+}$has transformed into $\mathrm{Ag}_{2} \mathrm{O}$. The XPS of N1s of Ag-CDs at the same $\mathrm{pH}$ values is shown in Figure $4 \mathrm{~b}$. At a pH of 1.72 , the amino group mainly exists in $-\mathrm{NH}_{3}{ }^{+}$form, and the positive charge causes the $\mathrm{BE}$ of N1s to be the highest one (black line in Figure $4 \mathrm{~b}$ ). When the $\mathrm{pH}$ is at 2.25 (red line in Figure $4 \mathrm{~b}$ ), the transition from $-\mathrm{NH}_{3}{ }^{+}$to coordination with $\mathrm{Ag}^{+}$results in a free $-\mathrm{NH}_{2}$-like state. This is very close to the extremely alkaline state ( $\mathrm{pH} 12.97$, brown line in Figure $4 \mathrm{~b}$ ) since all the $-\mathrm{NH}_{2}$ becomes free again due to the almost-complete precipitation of $\mathrm{Ag}_{2} \mathrm{O}$. When the $\mathrm{pH}$ is neutral or at 11.10 (blue and green lines in Figure $4 \mathrm{~b}$ ), the coordination state as $\mathrm{Ag}\left(-\mathrm{NH}_{2}\right)_{2}$ has middle $\mathrm{BE}$ values between free $-\mathrm{NH}_{2}$ and $-\mathrm{NH}_{3}{ }^{+}$states since the positive charge of $\mathrm{Ag}^{+}$has a weaker binding capability to electrons than that of $\mathrm{H}^{+}$but a larger one than a free $-\mathrm{NH}_{2}$ state. When the $\mathrm{pH}$ is at 12.15 , the amine group is at the transition state of 
$\mathrm{Ag}\left(-\mathrm{NH}_{2}\right) \mathrm{OH}$, and the electron donation effect of a negative charge of ${ }^{-} \mathrm{OH}$ weakens the bound capability of $\mathrm{Ag}^{+}$to electron compared with that at $\mathrm{Ag}\left(-\mathrm{NH}_{2}\right)_{2}$ state. That is why the $\mathrm{BE}$ value at $\mathrm{pH} 12.15$ (purple lines in Figure 4b) is smaller than that at a neutral state.

\subsection{Fluorescent Reversibility Ag-CDs upon the Variation in $p H$}

The very bright fluorescence emission of Ag-CDs at $\mathrm{pH} 12.15$ and the sensitive $\mathrm{pH}$ effect on fluorescence probed at $450 \mathrm{~nm}$, as shown above, drove us to explore the potential of Ag-CDs used as a fluorescent probe at extremely alkaline $\mathrm{pH}$ values. Figure 5 presents the repeatability and reversibility test of fluorescent intensity changing between $\mathrm{pH} 2.25$ and 12.15. The as-prepared Ag-CDs are subjected to $\mathrm{pH}$ cycling between $\mathrm{pH}=12.15$ and $\mathrm{pH}=2.25$ using $\mathrm{NaOH}$ and $\mathrm{H}_{2} \mathrm{SO}_{4}$ solutions repeatedly. As shown in Figure 5, the fluorescence intensities decrease significantly upon a $\mathrm{pH}$ change from 12.15 to 2.25. Afterwards, the FL intensity was restored nearly as before when the $\mathrm{pH}$ was changed back from 2.25 to 12.15. The luminescence switching operation could be repeated for four consecutive cycles without fatigue, indicating the good reversibility of the $\mathrm{pH}$ fluorescent sensor based on Ag-CDs. The photo-stability of Ag-CDs was evaluated by continuously measuring the fluorescence intensity probed at 400 and $450 \mathrm{~nm}$, respectively, under excitation at $360 \mathrm{~nm}$. The results are shown in Figure S2 in Supplementary Materials, which indicated that Ag-CDs prepared in this research have good photo-stability [16,29].

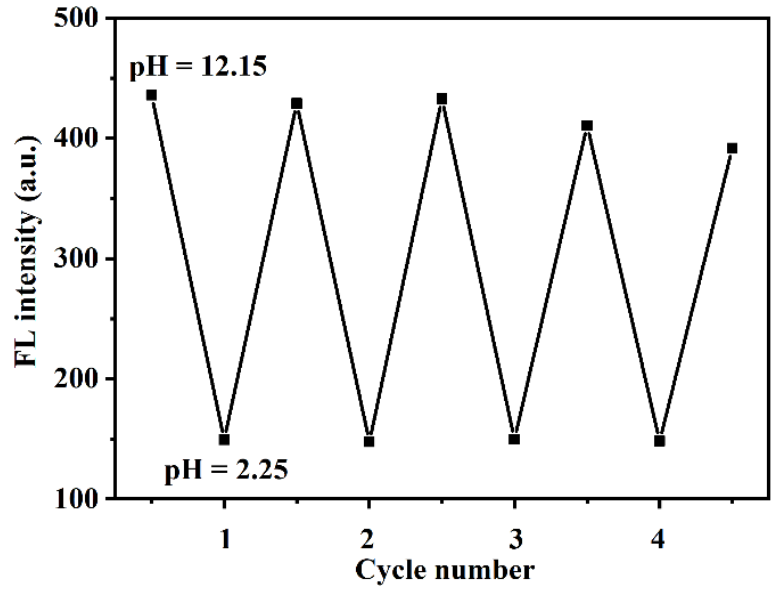

Figure 5. Fluorescence intensity probed at $450 \mathrm{~nm}$ upon the cyclic switching of Ag-CDs under alternating conditions of $\mathrm{pH}=12.15$ and $\mathrm{pH}=2.25\left(\lambda_{\mathrm{EX}}=360 \mathrm{~nm}\right)$.

This result implies that Ag-CDs in this research have good reversibility upon variation in $\mathrm{pH}$ values, which facilitates it to be developed as a fluorescent sensor practically at a very broad $\mathrm{pH}$ range.

\section{6. $p H$ Fluorescent Test Paper}

As displayed in Figure 6a, the filter paper was soaked in Ag-CDs solutions and dried to obtain the $\mathrm{pH}$ fluorescent test paper, and the fluorescent photograph was taken upon excitation at $365 \mathrm{~nm}$. The prepared $\mathrm{pH}$ fluorescent test papers were then soaked in water samples, including blank and the ultrapure water samples at various $\mathrm{pH}$ values $(11.15,12.20$, and 13.02), and were taken out immediately. The photographs were taken under excitation at $365 \mathrm{~nm}$. From Figure 6b(a-3), compared with other test papers, the $\mathrm{pH}$ fluorescent test paper soaked in ultrapure water at $\mathrm{pH}=12.20$ showed the brightest fluorescence, indicating that the $\mathrm{pH}$ fluorescent test paper could be a sensitive $\mathrm{pH}$-sensing device under strongly alkaline conditions. After $10 \mathrm{~min}$ under daylight, the $\mathrm{pH}$ fluorescent test paper was measured again, and the results shown in Figure $6 b(a-4)$ indicated very good photo-stability of the prepared fluorescent sensor based on Ag-CDs. In addition, the $\mathrm{pH}$ fluorescent test paper was evaluated in a real sample, i.e., tap water, too. As shown in Figure $6 b(b-3)$, the results for sensing $\mathrm{pH}$ variation in tap water were consistent with 
those in ultrapure water. This result proves that the $\mathrm{pH}$ fluorescent test paper based on Ag-CDs prepared here could be developed into a $\mathrm{pH}$ sensor with practical applications under strongly alkaline conditions.
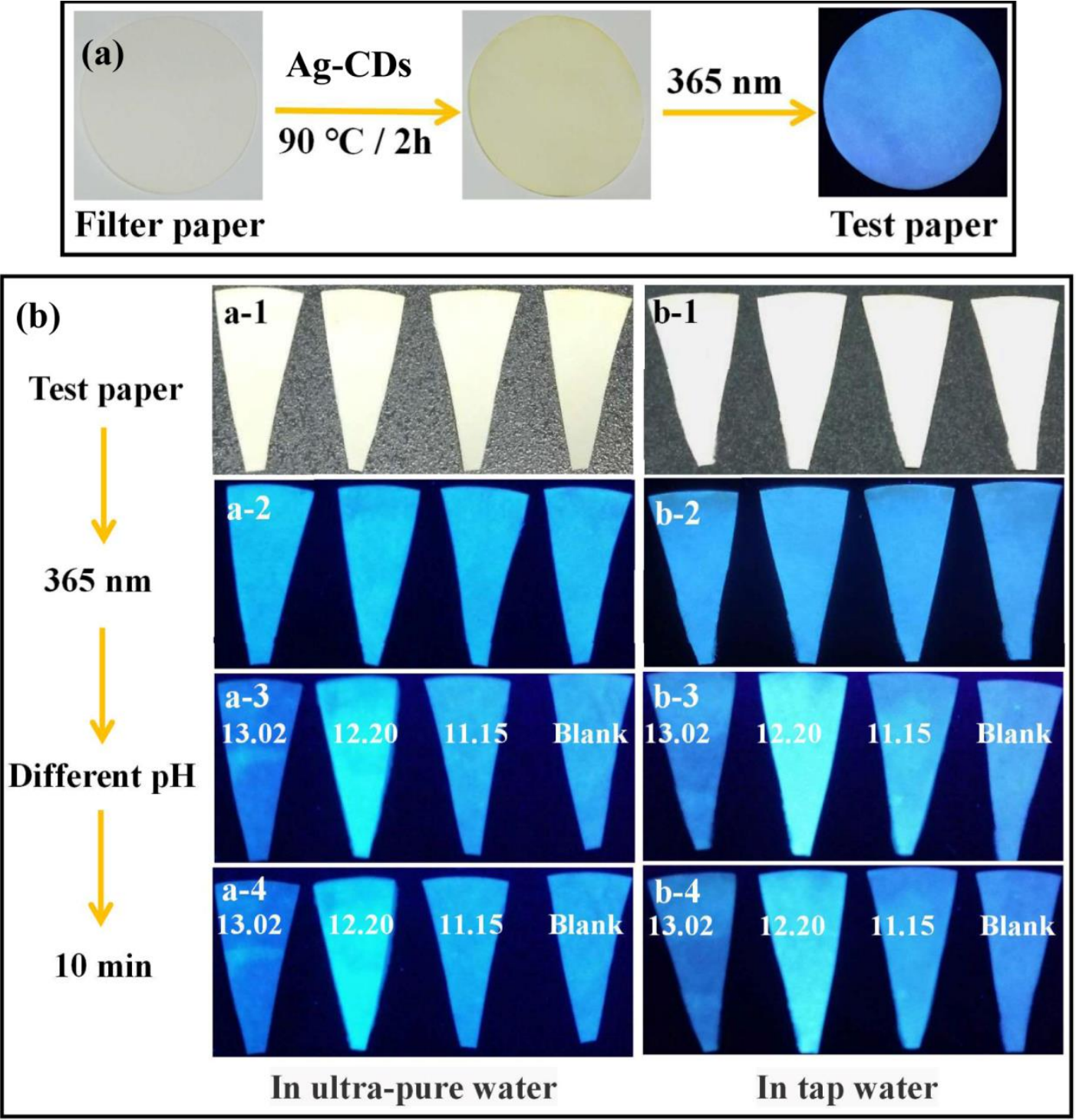

Figure 6. (a) The $\mathrm{pH}$ fluorescent test paper was prepared by filter paper and Ag-CDs (excited at $365 \mathrm{~nm}$ ). (b) The $\mathrm{pH}$ fluorescent test paper for different $\mathrm{pH}$ sensing (13.02, 12.20, 11.15, and Blank) in ultrapure water and tap water for $10 \mathrm{~min}$ (excited at $365 \mathrm{~nm}$ ).

\section{Conclusions}

The $\mathrm{Ag}^{+}$-doped CDs were synthesized through the hydrothermal method in this work. The structural mechanism has been studied through various spectroscopic methods under a broad range of $\mathrm{pH}$ values. The primary amine, carboxyl groups, and $\mathrm{Ag}^{+}$were determined to coexist in the as-prepared Ag-CDs by FT-IR and XPS. The electronic absorption origins of the two fluorescent species in the neutral solution have been assigned through a comparison between fluorescent emission and excitation spectra. With the assistance of XPS at various $\mathrm{pH}$ values, the $\mathrm{pH}$-regulating fluorescence mechanism was proposed. The most interesting finding is a very bright fluorescent species observed at $\mathrm{pH} 12.15$, and the further fluorescent reversibility test upon $\mathrm{pH}$ variation and the $\mathrm{pH}$ fluorescent test paper prove that the Ag-CDs prepared in this study might be developed into a fluorescent sensor, especially at extremely 
basic conditions. This work also paves the road for developing a similar pH-regulated metal ion-doped CDs-based fluorescent sensor.

Supplementary Materials: The following supporting information can be downloaded at: https: / / www.mdpi.com/article/10.3390/ma15051880/s1, Figure S1. XPS spectrum of Ag-CDs. Figure S2. The photo-stability test. The fluorescence intensities of Ag-CDs were continuously measured for $180 \mathrm{~s}$ at 400 and $450 \mathrm{~nm}$ under excitation at $360 \mathrm{~nm}$. Figure S3. (a) Photographs of Ag-CDs at different $\mathrm{pH}$ (10.20-13.95) under daylight (I) and UV light (II, excited at $365 \mathrm{~nm}$ ). (b) The fluorescence spectrum of Ag-CDs at different $\mathrm{pH}, \lambda \mathrm{ex}=360 \mathrm{~nm}$, respectively. (c) The fluorescence intensities at 400 and $450 \mathrm{~nm}$ of Ag-CDs at different $\mathrm{pH}, \lambda \mathrm{ex}=360 \mathrm{~nm}$, respectively; Figure S4. The fluorescence lifetime of Ag-CDs; Figure S5. (a) Photographs of Ag-CDs containing metal ions $\left(\mathrm{Ba}^{2+}, \mathrm{Ca}^{2+}, \mathrm{Co}^{2+}, \mathrm{Cr}^{3+}, \mathrm{Cu}^{2+}\right.$, $\mathrm{Fe}^{2+}, \mathrm{K}^{+}, \mathrm{Mg}^{2+}, \mathrm{Mn}^{2+}, \mathrm{Na}^{+}, \mathrm{Ni}^{2+}, \mathrm{Pb}^{2+}$ and $\mathrm{Zn}^{2+}, 1 \mathrm{mM}$ ) under daylight (up) and $\mathrm{UV}$ light (down, excited at $365 \mathrm{~nm}$ ). Fluorescence emission spectra (b) and normalized fluorescence intensities (c) of Ag-CDs containing metal ions $\left(\mathrm{Ba}^{2+}, \mathrm{Ca}^{2+}, \mathrm{Co}^{2+}, \mathrm{Cr}^{3+}, \mathrm{Cu}^{2+}, \mathrm{Fe}^{2+}, \mathrm{K}^{+}, \mathrm{Mg}^{2+}, \mathrm{Mn}^{2+}, \mathrm{Na}^{+}, \mathrm{Ni}^{2+}, \mathrm{Pb}^{2+}\right.$ and $\left.\mathrm{Zn}^{2+}, 1 \mathrm{mM}\right), \lambda \mathrm{ex}=360 \mathrm{~nm}$; Figure S6. High-resolution XPS spectra of Ag3d of Ag-CDs at $\mathrm{pH}$ 1.32 (a), 2.25 (b), Ag-CDs (c), 11.10 (d), 12.15 (e), 12.97 (f), respectively; Figure S7. High-resolution XPS spectra of N1s of Ag-CDs at pH 1.32 (a), 2.25 (b), Ag-CDs (c), 11.10 (d), 12.15 (e), 12.97 (f), respectively; Table S1 $[6,22,24,43-48]$. Comparisons of $\mathrm{pH}$ sensing range of various fluorescent probes based on carbon dots.

Author Contributions: Data curation, Q.X. and K.L.; Formal analysis, Q.X. and P.W.; Methodology, Q.X. and P.W.; Validation, Q.X. and P.W.; Writing—original draft, Q.X. and K.L.; Writing—review and editing, P.W. All authors have read and agreed to the published version of the manuscript.

Funding: This work has been supported by the National Natural Science Foundation of China Nos. 21673289, 22073113.

Institutional Review Board Statement: Not applicable.

Informed Consent Statement: Not applicable.

Data Availability Statement: The data will be made available on request.

Acknowledgments: This work has been supported by the National Natural Science Foundation of China Nos. 21673289, 22073113.

Conflicts of Interest: The authors declare that there are no conflict of interest.

\section{References}

1. Lim, S.-Y.; Shen, W.; Gao, Z.-Q. Carbon quantum dots and their applications. Chem. Soc. Rev. 2015, 44, 362-381. [CrossRef]

2. Wang, Y.; Hu, A. Carbon quantum dots: Synthesis, properties and applications. J. Mater. Chem. C 2014, 2, 6921-6939. [CrossRef]

3. Mansuriya, B.D.; Altintas, Z. Carbon Dots: Classification, Properties, Synthesis, Characterization, and Applications in Health Care-An Updated Review (2018-2021). Nanomaterials 2021, 11, 2525. [CrossRef] [PubMed]

4. Jorns, M.; Pappas, D. A Review of Fluorescent Carbon Dots, Their Synthesis, Physical and Chemical Characteristics, and Applications. Nanomaterials 2021, 11, 1448. [CrossRef] [PubMed]

5. Khan, S.; Gupta, A.; Verma, N.C.; Nandi, C.K. Time-Resolved Emission Reveals Ensemble of Emissive States as the Origin of Multicolor Fluorescence in Carbon Dots. Nano Lett. 2015, 15, 8300-8305. [CrossRef] [PubMed]

6. Nie, H.; Li, M.; Li, Q.; Liang, S.; Tan, Y.; Sheng, L.; Shi, W.; Zhang, S.X.-A. Carbon Dots with Continuously Tunable Full-Color Emission and Their Application in Ratiometric pH Sensing. Chem. Mater. 2014, 26, 3104-3112. [CrossRef]

7. Wen, X.; Yu, P.; Toh, Y.-R.; Hao, X.; Tang, J. Intrinsic and Extrinsic Fluorescence in Carbon Nanodots: Ultrafast Time-Resolved Fluorescence and Carrier Dynamics. Adv. Opt. Mater. 2013, 1, 173-178. [CrossRef]

8. Wang, L.; Zhu, S.; Wang, H.-Y.; Qu, S.-N.; Zhang, Y.-L.; Zhang, J.; Chen, Q.-D.; Xu, H.-L.; Han, W.; Yang, B.; et al. Common Origin of Green Luminescence in Carbon Nanodots and Graphene Quantum Dots. ACS Nano 2014, 8, 2541-2547. [CrossRef] [PubMed]

9. Lei, C.-W.; Hsieh, M.-L.; Liu, W.-R. A facile approach to synthesize carbon quantum dots with pH-dependent properties. Dyes Pigments 2019, 169, 73-80. [CrossRef]

10. Sharma, A.; Gupta, T.G.A.; Ballal, A.; Ghosh, S.K.; Kumbhakar, M. Origin of Excitation Dependent Fluorescence in Carbon Nanodots. J. Phys. Chem. Lett. 2016, 7, 3695-3702. [CrossRef]

11. Li, X.; Zhang, S.; Kulinich, S.; Liu, Y.; Zeng, H. Engineering surface states of carbon dots to achieve controllable luminescence for solid-luminescent composites and sensitive Be ${ }^{2+}$ detection. Sci. Rep. 2014, 4, 4976. [CrossRef]

12. Zhang, R.; Chen, W. Nitrogen-doped carbon quantum dots: Facile synthesis and application as a "turn-off" fluorescent probe for detection of $\mathrm{Hg}^{2+}$ ions. Biosens. Bioelectron. 2014, 55, 83-90. [CrossRef] 
13. Pathak, A.; Venugopal, P.; Nair, B.G.; Suneesh, P.V.; Babu, S.T.G. Facile pH-sensitive optical detection of pathogenic bacteria and cell imaging using multi-emissive nitrogen-doped carbon dots. Microchem. J. 2020, 159, 105324. [CrossRef]

14. Khan, W.U.; Wang, D.; Wang, Y. Highly Green Emissive Nitrogen-Doped Carbon Dots with Excellent Thermal Stability for Bioimaging and Solid-State LED. Inorg. Chem. 2018, 57, 15229-15239. [CrossRef]

15. Barati, A.; Shamsipur, M.; Abdollahi, H. Carbon dots with strong excitation-dependent fluorescence changes towards $\mathrm{pH}$. Application as nanosensors for a broad range of pH. Anal. Chim. Acta 2016, 931, 25-33. [CrossRef]

16. Mondal, T.K.; Saha, S.K. Facile Approach To Synthesize Nitrogen- and Oxygen-Rich Carbon Quantum Dots for pH Sensor, Fluorescent Indicator, and Invisible Ink Applications. ACS Sustain. Chem. Eng. 2019, 7, 19669-19678. [CrossRef]

17. Zhang, X.-Q.; Chen, C.-Y.; Peng, D.-P.; Zhou, Y.-Z.; Zhuang, J.-L.; Zhang, X.-J.; Lei, B.-F.; Liu, Y.-L.; Hu, C.-F. pH-Responsive carbon dots with red emission for real-time and visual detection of amines. J. Mater. Chem. C 2020, 8, 11563-11571. [CrossRef]

18. Sun, X.-F.; Chen, M.-J.; Zhang, Y.-Q.; Yin, Y.-J.; Zhang, L.-W.; Li, H.-G.; Hao, J.-C. Photoluminescent and pH-Responsive Supramolecular Structures from Co-assembly of Carbon Quantum Dots and Zwitterionic Surfactant Micelles. J. Mater. Chem. B 2018, 6, 7021-7032. [CrossRef] [PubMed]

19. Hao, Y.; Gan, Z.; Zhu, X.; Li, T.; Wu, X.; Chu, P.K. Emission from Trions in Carbon Quantum Dots. J. Phys. Chem. C 2015, 119, 2956-2962. [CrossRef]

20. Chauhan, P.; Mundekkad, D.; Mukherjee, A.; Chaudhary, S.; Umar, A.; Baskoutas, S. Coconut Carbon Dots: Progressive LargeScale Synthesis, Detailed Biological Activities and Smart Sensing Aptitudes towards Tyrosine. Nanomaterials 2022, $12,162$. [CrossRef] [PubMed]

21. Kalaiyarasan, G.; Joseph, J. Determination of vitamin B12 via pH-dependent quenching of the fluorescence of nitrogen doped carbon quantum dots. Microchim. Acta 2017, 184, 3883-3891. [CrossRef]

22. Ma, Z.; Ma, Y.; Gu, M.; Huo, X.; Ma, S.; Lu, Y.; Ning, Y.; Zhang, X.; Tian, B.; Feng, Z. Carbon Dots Derived from the Maillard Reaction for pH Sensors and Cr (VI) Detection. Nanomaterials 2020, 10, 1924. [CrossRef]

23. Das, P.; Maruthapandi, M.; Saravanan, A.; Natan, M.; Jacobi, G.; Banin, E.; Gedanken, A. Carbon Dots for Heavy-Metal Sens-ing, pH-Sensitive Cargo Delivery, and Antibacterial Applications. ACS Appl. Nano Mater. 2020, 3, 11777-11790. [CrossRef]

24. Wang, C.; Xu, Z.; Zhang, C. Polyethyleneimine-Functionalized Fluorescent Carbon Dots: Water Stability, pH Sensing, and Cellular Imaging. ChemNanoMat 2015, 1, 122-127. [CrossRef]

25. Qian, Z.; Ma, J.; Shan, X.; Feng, H.; Shao, L.; Chen, J. Highly Luminescent N-Doped Carbon Quantum Dots as an Effective Multifunctional Fluorescence Sensing Platform. Chem. A Eur. J. 2014, 20, 2254-2263. [CrossRef]

26. Gao, X.-H.; Lu, Y.-Z.; Zhang, R.-Z.; He, S.-J.; Ju, J.; Liu, M.-M.; Li, L.; Chen, W. One-pot synthesis of carbon nanodots for fluo-rescence turn-on detection of $\mathrm{Ag}+$ based on the $\mathrm{Ag}^{+}$-induced enhancement of fluorescence. J. Mater. Chem. C 2015, 3 , 2302-2309. [CrossRef]

27. Li, C.; Zhang, X.; Zhang, W.; Qin, X.; Zhu, C. Carbon quantum dots derived from pure solvent tetrahydrofuran as a fluorescent probe to detect $\mathrm{pH}$ and silver ion. J. Photochem. Photobiol. A Chem. 2019, 382, 111981. [CrossRef]

28. Zhuo, S.J.; Fang, J.; Wang, J.; Zhu, C.-Q. One-step hydrothermal synthesis of silver-doped carbon quantum dots for highly selective detection of uric acid. Methods Appl. Fluoresc. 2020, 8, 015005. [CrossRef] [PubMed]

29. Shekarbeygi, Z.; Karami, C.; Esmaeili, E.; Moradi, S.; Shahlaei, M. Development of Ag nanoparticle-carbon quan-tum dot nanocomplex as fluorescence sensor for determination of gemcitabine. Spectrochim. Acta Part A Mol. Biomol. Spectrosc. 2021, 262, 120148. [CrossRef] [PubMed]

30. Kim, B.G.; Nguyen, D.D.; Jang, W.; Kim, J.K.; Wang, D.H. Formulation of conductive nanocomposites by incorporating silverdoped carbon quantum dots for efficient charge extraction. Int. J. Energy Res. 2021, 45, 21324-21339. [CrossRef]

31. Yang, S.-W.; Sun, J.; Li, X.-B.; Zhou, W.; Wang, Z.-Y.; He, P.; Ding, G.-Q.; Xie, X.-M.; Kang, Z.-H.; Jiang, M.-H. Large-scale fab-rication of heavy doped carbon quantum dots with tunable-photoluminescence and sensitive fluorescence detection. J. Mater. Chem. A 2014, 2, 8660-8667. [CrossRef]

32. Gong, X.; Lu, W.; Paau, M.C.; Hu, Q.; Wu, X.; Shuang, S.; Dong, C.; Choi, M.M. Facile synthesis of nitrogen-doped carbon dots for $\mathrm{Fe}^{3+}$ sensing and cellular imaging. Anal. Chim. Acta 2015, 861, 74-84. [CrossRef] [PubMed]

33. Zhang, B.; Yang, Q.; Li, Z.; Hao, J. Green synthesis of luminescent carbon dots and carbon-coated metal particles: Two birds with one stone. Colloids Surf. A Physicochem. Eng. Asp. 2015, 485, 34-41. [CrossRef]

34. Bischoff, D.; Varlet, A.; Simonet, P.; Eich, M.; Overweg, H.C.; Ihn, T.; Ensslin, K. Localized charge carriers in graphene nanodevices. Appl. Phys. Rev. 2015, 2, 031301. [CrossRef]

35. Vijayan, V.M.; Komeri, R.; Victor, S.P.; Muthu, J. Photoluminescent PEG based comacromers as excitation dependent fluor-ophores for biomedical applications. Colloids Surf. B Biointerfaces 2015, 135, 243-252. [CrossRef]

36. Park, H.; Noh, S.H.; Lee, J.H.; Lee, W.J.; Jaung, J.Y.; Lee, S.G.; Han, T.H. Large Scale Synthesis and Light Emitting Fibers of Tailor-Made Graphene Quantum Dots. Sci. Rep. 2015, 5, 14163. [CrossRef]

37. Wu, Z.; Feng, M.; Chen, X.; Tang, X. N-dots as a photoluminescent probe for the rapid and selective detection of $\mathrm{Hg}^{2+}$ and $\mathrm{Ag}^{+}$in aqueous solution. J. Mater. Chem. B 2016, 4, 2086-2089. [CrossRef]

38. Zhou, Z.-X.; Shen, Y.-F.; Li, Y.; Liu, A.-R.; Liu, S.-Q.; Zhang, Y.J. Chemical Cleavage of Layered Carbon Nitride with Enhanced Photoluminescent Performances and Photoconduction. ACS Nano 2015, 9, 12480-12487. [CrossRef] 
39. Li, H.; Sun, C.; Vijayaraghavan, R.; Zhou, F.; Zhang, X.; MacFarlane, D.R. Long lifetime photoluminescence in N, S co-doped carbon quantum dots from an ionic liquid and their applications in ultrasensitive detection of pesticides. Carbon 2016, 104, 33-39. [CrossRef]

40. Fan, X.; Qin, X.; Jing, L.; Luan, Y.; Xie, M. Controllable synthesis of floatable nanocrystalline $\mathrm{Ag}_{2} \mathrm{~S}$ and $\mathrm{Ag}$ by a silane coupling agent-modified solvothermal method. Mater. Res. Bull. 2012, 47, 3732-3737. [CrossRef]

41. Bao, L.; Zhang, Z.-L.; Tian, Z.-Q.; Zhang, L.; Liu, C.; Lin, Y.; Qi, B.-P.; Pang, D.W. Electrochemical tuning of luminescent car-bon nanodots: From preparation to luminescence mechanism. Adv. Mater. 2011, 23, 5801-5806. [CrossRef] [PubMed]

42. Wang, Z.-X.; Ding, S.-N. One-pot green synthesis of high quantum yield oxygen-doped, nitrogen-rich, photoluminescent polymer carbon nanoribbons as an effective fluorescent sensing platform for sensitive and selective detection of silver (I) and mercury (II) ions. Anal. Chem. 2014, 86, 7436-7445. [CrossRef] [PubMed]

43. Shangguan, J.-F.; He, D.-G.; He, X.-X.; Wang, K.-M.; Xu, F.-Z.; Liu, J.-Q.; Tang, J.-L.; Yang, X.; Huang, J. Label-free carbondots-based ratiometric fluorescence $\mathrm{pH}$ nanoprobes for intracellular $\mathrm{pH}$ sensing. Anal. Chem. 2016, 88, 7837-7843. [CrossRef] [PubMed]

44. Hai, X.; Wang, Y.-T.; Hao, X.-Y.; Wang, J.-H. Folic acid encapsulated graphene quantum dots for ratiometric $\mathrm{pH}$ sensing and specific multicolor imaging in living cells. Sens. Actuators B Chem. 2018, 268, 61-69. [CrossRef]

45. Wang, C.-X.; Xu, Z.-Z.; Cheng, H.; Lin, H.-H.; Humphrey, M.-G.; Zhang, C. A hydrothermal route to water-stable luminescent carbon dots as nanosensors for $\mathrm{pH}$ and temperature. Carbon 2015, 82, 87-95. [CrossRef]

46. Du, F.-K.; Ming, Y.H.; Zeng, F.; Yu, C.-G.; Wu, S.-Z. A low cytotoxic and ratiometric fluorescent nanosensor based on carbon-dots for intracellular pH sensing and mapping. Nanotechnology 2013, 24, 365101. [CrossRef]

47. Liao, S. Huang, X.-Q. Yang, H.; Chen, X.-Q. Nitrogen-doped carbon quantum dots as a fluorescent probe to detect copper ions, glutathione, and intracellular pH. Anal. Bioanal. Chem. 2018, 410, 7701-7710. [CrossRef]

48. Sun, Y.-Q.; Wang, X.-J.; Wang, C.; Tong, D.-Y.; Wu, Q.; Jiang, K.-L.; Jiang, Y.-N; Wang, C.-X.; Yang, M.-H. Red emitting and highly stable carbon dots with dual response to $\mathrm{pH}$ values and ferric ions. Microchim. Acta 2018, 185, 83. [CrossRef] 